\title{
LA MOTIVACIÓN LÉXICA EN EL ÁMBITO DE LA GLOSODIDÁCTICA
}

\author{
Juan Manuel García Platero \\ Universidad de Sevilla \\ jugarcia@us.es
}

Recibido: $15 / 12 / 2014$

Aceptado: 13/04/2015

\begin{abstract}
Resumen
En la enseñanza y aprendizaje del léxico de una segunda lengua están presentes factores muy diversos, por lo que se requiere de un tratamiento específico y complementario. En este trabajo se analizan los mecanismos de motivación relativa de las palabras, tanto desde la perspectiva intralingüística como atendiendo a las relaciones de semejanza y contigüidad. Se trata de intentar, en la medida de lo posible, aminorar de la opacidad léxica alentando una reflexión metalingüística, de especial interés para los aprendices de la lengua meta.

PALABRAS CLAVE: Glosodidáctica, léxico, lexicogénesis, metáfora, metonimia.
\end{abstract}

\begin{abstract}
Teaching and learning second language lexicon requires a specific and complementary treatment due to the different factors involved. In this paper, specific mechanisms of relative motivation for words are analysed. With this aim in mind the intralingual viewpoint and similarity and contiguity relationships will be taken into account. The main goal is to reduce lexical opacity encouraging students to accomplish metalinguistic reflections which are of particular interest to students of the target language.

KEY WORDS: Language methodology, lexicon, word formation, metaphor, metonymy.
\end{abstract}

\section{Introducción}

No son pocos los trabajos en los que se ponen de manifiesto las dificultades del docente para conseguir un objetivo determinado en la enseñanza de una segunda lengua (Benítez Pérez, 1994; Baralo, 2003; Santamaría Pérez, 2006) sobre todo en el nivel léxico. Aún más numerosas son las propuestas, con frecuencia imaginativas y no siempre pertinentes (visibles en congresos o revistas especializadas en el ámbito glosodidáctico), que, desde diferentes enfoques, pretenden incidir en ciertos aspectos lingüísticos y culturales y subsanar carencias. En todo caso, existe una realidad fácilmente verificable, al margen de las muy diversas circunstancias espaciotemporales: la clasificación por niveles de conocimiento no refleja con veracidad el dominio léxico. Se trata de un problema al que los docentes especializados en la adquisición de vocabulario se enfrentan con más frecuencia de la deseable.

No es este el lugar adecuado para poner en entredicho las sutiles descripciones que impone el establecimiento de compartimentos estancos en el continuo léxico, pero lo cierto es que las discreciones morfosintácticas, e incluso fonéticas, no guardan parangón con el complejo universo de la adquisición de vocabulario. Es habitual encontrarnos con disparidades dentro de un mismo estatuto de dominio lingüístico, pues en los procesos de enseñanza y aprendizaje los distintos enfoques hacen hincapié, marcados por inevitables urgencias, en la adquisición 
de competencias gramaticales y en un léxico instrumental, al que se adicionan paulatinamente unidades derivadas de necesidades genéricas o específicas. Y aunque es una obviedad que la enseñanza y aprendizaje no se circunscriben a los niveles iniciales, con frecuencia se desdeña el manejo de algunas voces, e incluso de procedimientos lexicogenésicos, al no incluirse entre las herramientas esenciales de comunicación, tal vez por una identificación basada en la frecuente demanda de un tipo determinado de alumnado. Pero el problema radica en la necesidad de abarcar realidades más complejas. Si a esto le añadimos que se trabaja con ejercicios orientados preferentemente al manejo morfosintáctico, por lo que de forma colateral se incluyen en los textos correspondientes unidades circunscritas a registros o niveles lingüísticos heterogéneos (con los correspondientes problemas de inflación o déficit léxicos, según los casos, sin olvidar las confusiones dentro del continuo diastrático-diafásico), se concluye que el aprendizaje de vocabulario carece de una adecuada sistematización ${ }^{1}$.

No se trata de suposiciones, sino de datos extraídos del quehacer cotidiano, ya que no resulta raro que se detecten contradicciones en la etiquetación del nivel de conocimiento del discente. De hecho, desde la perspectiva de la disponibilidad, aunque se observe, obviamente, que un mayor nivel de aprendizaje implica un conocimiento de vocabulario más amplio, no se reconoce homogeneidad de crecimiento en la adquisición de unidades léxicas, dado que la proporción entre los ciclos iniciales e intermedios no se corresponde con lo aprendido en el avanzado (Sánchez-Saus Laserna, 2010). De ahí que alumno muestre impotencia al enfrentarse a las lagunas léxicas, sin olvidar las irregularidades en determinados actos discursivos ${ }^{2}$. En ese sentido, es habitual que el aprendiz ubicado en un conocimiento idiomático medio, e incluso alto, tienda al recurso hiperonímico. Sin negar la plurivalidez referencial de las unidades archilexemáticas, básica para los primeros ciclos de formativos, es obvio que resultan insuficientes para grados superiores, pues el hablante muestra pobreza expresiva al ignorar elementos sustitutivos parasinonímicos. No hay que olvidar que las tareas orientadas al aprendizaje de sustituciones estilísticas no son nada desdeñables, en la medida en que se consigue la consolidación de dominio léxico, por lo que están generalmente presentes en gran parte de los métodos de idiomas. Y no cabe duda de que el escaso dominio discursivo del vocabulario ocasiona no pocas inadecuaciones ante determinadas sinfasías, por lo que el docente ha de suplir las lógicas carencias de un material didáctico que no puede abarcar dimensiones pragmáticas heterogéneas. En este, como en otros casos, las dificultades en el manejo léxico pueden mitigarse con la elaboración de actividades que complementen los estándares inicialmente propuestos, ya que, como suele suceder la mayoría de las veces, se parte de métodos idiomáticos de amplio espectro en los que se vislumbra un aprendizaje implícito de vocabulario, sin la sistematicidad y adecuación pragmáticas ${ }^{3}$, que únicamente se consiguen con una selección pertinente de las unidades (Bartol Hernández, 2010).

1 Con respecto a los ejemplos de inadecuación léxica en los manuales de aprendizaje, cfr. Benítez Pérez (1994). Para la multiplicidad de factores que entran en juego en la competencia léxica, debe verse el trabajo de Santamaría Pérez (2006).

2 No me refiero únicamente a la tradicional didáctica en el aula, pues la experiencia de llevar a cabo iniciativas de asesoramiento para el aprendizaje de lenguas con metodología tándem evidencia problemas en el adecuado intercambio léxico entre los participantes. Para esta perspectiva de enseñanza, cfr. Morán Manso (1998).

3 Es innegable que las situaciones pueden ser muy diversas, tanto para el docente como para el aprendiz, ya que, al margen, evidentemente, del grado de conocimiento idiomático de este último, los resultados dependerán de si ambos están ubicados o no en el espacio geográfico donde se habla la lengua meta. Una vez más el nivel léxico será el más condicionado por la realidad del aula. 
Conviene subrayar que no me refiero a carencias de una obra concreta, sino a un hábito consagrado. En ese sentido, se han consultado para la elaboración de este trabajo los manuales de aprendizaje de mayor difusión, en los diferentes niveles de adquisición lingüística. No es mi propósito reseñarlos, dado que, en la medida de sus posibilidades, cumplen una función de acuerdo con los parámetros trazados para una adquisición genérica de los resortes descodificadores. Y pese a que dichas obras puedan complementarse con otras que incluyan tareas orientadas específicamente al conocimiento de vocabulario, el problema radica en que se necesita una intervención más directa y concienciada del docente con la finalidad de paliar lo que, de forma inevitable, conllevan estos instrumentos de aprendizaje: carencias codificadoras derivadas del alejamiento discursivo. Esto también ocurre, salvando las distancias, con los repertorios lexicográficos monolingües, pensados para los alumnos que aprenden, en el nivel de conocimiento propicio, una segunda lengua, aunque no se pongan en duda sus indiscutibles ventajas (Martín García, 1999; Alvar Ezquerra, 2003; García Platero, 2010). Es lógico pensar que toda etiquetación léxica es meramente aproximativa, dada la adiscursividad de lo catalogado. Incluso si hablamos de aprendizaje con fines específicos, podemos caer en excesivas simplificaciones que no tienen en cuenta que las circunstancias comunicativas son muy variables y no han de reducirse a una sinstratía desnaturalizada. Es decir, nos encontramos con generalizaciones de empleo que constriñen una realidad compleja por heterogénea. En la medida en que en la enseñanza de las unidades léxicas se parte, de forma inevitable, de elementos deshabitados, al margen de su veracidad discursiva, por mucho que se intente paliar con propuestas muy diversas, el problema se acrecienta cuando las intercomunicaciones se extienden más allá del ámbito de una unidad didáctica ${ }^{4}$.

Pese a estas dificultades, nacidas de la preeminencia incidental en el aprendizaje del vocabulario, si entendemos que toda discreción teórica, dentro de la continuidad léxica que manifiesta la observación cotidiana de la interacción comunicativa, ocasiona una actuación consciente restitutiva, es pertinente establecer las relaciones léxicas necesarias (tanto en su organización horizontal, el universo fraseológico, incluida la coaparición de unidades léxi$\mathrm{cas}^{5}$, como en la verticalidad paradigmática ${ }^{6}$ y buscar contextualizaciones fidedignas ${ }^{7}$. Y es que la construcción de redes relaciones y su ulterior estabilización es el fundamento del aprendizaje léxico propio del hablante nativo (Escandell Vidal, 2007: 165-183).

4 De hecho, se detectan no pocas dificultades de manejo discursivo en alumnos de nivel, como apunté antes, avanzado, que, tras varios años de aprendizaje en su propio país, pretenden completar sus conocimientos fuera de su lugar de origen. Y no hablo de conjeturas, sino de la experiencia compartida con otros docentes.

5 Sin embargo, en el caso de las colocaciones la opacidad es manifiesta, dado que la elección del colocativo por parte de la base léxica deviene en seudodesemantización, en la medida en que, en no pocas ocasiones, salvo la tipicidad léxica, adquiere una función meramente intensificadora del contenido de la unidad seleccionadora (García Platero, 2002). Esta característica implica que las colocaciones entren a formar parte como esfera en el universo fraseológico, por más que se haya puesto en duda en alguna ocasión. Resulta innegable que el aprendiz, tal y como reflejan los distintos análisis de errores, se enfrenta a no pocos problemas de codificación en el caso de las unidades léxicas que coaparecen. Para la visión glosodidáctica, cfr. Castillo Carballo (2004), Higueras García (2006) y Alba Quiñones (2014). De la combinatoria léxica aplicada a fines específicos se han ocupado, entre otros, Vidal y Cabré (2005).

6 De hecho se ha defendido la reutilización de la teoría de los campos semánticos en el aprendizaje de lenguas (López Morales, 1992).

7 Incluso la multiplicidad significativa en el fenómeno polisémico implica la interrelación de contenidos, según la perspectiva baldingeriana, por más que este proceder implique no pocas subjetividades, por lo que la diferenciación entre variante e invariante significativas arroja más luz a la posible solución del problema. 
Este trabajo pretende centrarse en un aspecto concreto de la didáctica léxica, a sabiendas de que son muchas las propuestas que deben tenerse en cuenta para subsanar las carencias referidas. El análisis de la motivación léxica, entendida en el entorno sintagmático y asociativo del signo (Díaz Hormigo, 2009), resulta de interés en el ámbito en el que nos movemos, pues en circunstancias no propicias para la inmersión lingüística (desde los primeros años de formación) la adquisición de mecanismos que conforman la analogía sistemática, que tiende a reivindicarse como método de dominio de vocabulario para primera o segunda lengua (Martín Camacho, 2007), conlleva una minoración de la opacidad de las voces, especialmente eficaz para una retentiva lógicamente más limitada y urgente que la visible en el aprendizaje de lenguas nativas ${ }^{8}$. Se trata de la llamada "motivación intralingüística de carácter morfológico" (Penadés Martínez y Díaz Hormigo, 2008), por más que, en todo caso, la transparencia léxica siempre será, como bien sabemos, relativa. En este análisis, sin descartar otros estudios posteriores, fijo mi interés en la seudomotivación morfológica, los mecanismos intralingüísticos, aunque no pueden obviarse los casos de similitud y desplazamiento de tipo referencial ${ }^{9}$. Se defiende, en este sentido, un proceso de reflexión metalingüística en el aula, entendido como elemento mitigador del problema del déficit léxico ${ }^{10}$, aunque evidentemente no es el único ${ }^{11}$.

Conviene, finalmente, resaltar que no hay que entender estas reflexiones como una crítica a un método específico de aplicación en el aula. No son pocas las voces que, a la vez que lamentan el desinterés por el desarrollo de destrezas léxicas complementarias, defienden un eclepticismo metodológico paliativo de las carencias señaladas (Soler Albiñala, 2008).

8 Entre hablantes nativos, y al margen, obviamente, de contextos de aprendizaje, son numerosos los ejemplos de uso de la etimología popular, precisamente por la eterna búsqueda de la relación natural entre los componentes del signo (Méndez García de Paredes, 1993). La physis cratilense, frente a la dificultosa realidad de las relaciones por convención, puede, en un acto generalmente inconsciente de rebeldía lingüística ante lo opaco, ocasionar el consenso, visible en la sanción lexicográfica correspondiente (piénsese en olor de multitudes).

9 Obviamente el concepto de motivación presupone unos conocimientos y vivencias no necesariamente compartibles entre los individuos de una sociedad, por lo que no resulta objetivable, sobre todo cuando nos encontramos con determinadas sintopías (Jiménez Cuenca, 1999), y en especial en el universo fraseológico, con lógicos problemas, en este último caso, de transcodificación (Negro Alousque, 2010). Cabe señalar, incluso, que la perspectiva evolutiva, en los niveles de conocimiento pertinentes, resulta inevitable en el tratamiento de los dobletes léxicos cuando el contraste significativo de las unidades no se capta con facilidad (si la oposición entre el alcance de contenido literal y traslaticio no es sistematizable, en relación con el carácter popular o culto del vocablo). En estos casos, las adecuadas aclaraciones de tipo enciclopédico, con la consiguiente reflexión metalingüística, contrastiva o no, van orientadas a la minoración de la opacidad (Calví y Martinell, 1998)

10 De hecho, no es extraño que se hable, aunque desde una perspectiva esencialmente instrumental, de la necesidad del conocimiento metalingüístico en la clase de ELE, básica para el manejo idiomático en el aula, sobre todo cuando se aborda la interacción entre alumnos y profesores, el dominio de la terminología gramatical y la descodificación de las tareas de aprendizaje (Izquierdo Gil, 2005: 64-68). Para la importancia de las modificaciones interactivas en el contexto institucional del aula, cfr. Alcón Soler (2001).

11 En la Universidad de Sevilla imparto la asignatura "Competencias léxicas y terminológicas en español" a una treintena de alumnos de nivel B2. En la encuesta inicial les pido una autoevaluación de sus destrezas léxicas y que hagan hincapié en sus carencias y posibles causas. La mayor parte reconoce una disociación de conocimientos entre esta materia y otras relacionadas con la fonética o la gramática, pues los aprendientes no han recibido un tratamiento autónomo del vocabulario. Sin embargo, al finalizar el curso (un cuatrimestre) reconocen que su nivel de confianza en el empleo léxico ha aumentado y valoran positivamente la importancia codificadora de la reflexión metalingüística. Estos datos se repiten año tras año. 


\section{La relativización de lo motivado en la lexicogénesis}

Qué duda cabe de que el manejo de los diversos mecanismos lexicogenésicos resulta especialmente rentable, al ser las unidades derivadas los ejemplos más palpables de la llamada arbitrariedad relativa de los signos lingüísticos. De hecho, cuando se trabaja en el aula con corpus que priorizan los medios de comunicación, por su especial capacidad creativa (además de la lógica relación con la realidad cultural y política de la sociedad en la que se habla la lengua meta), más que la voz neológica en sí misma es relevante la captación del proceso formativo. Es decir, al margen de la importancia de las palabras testigo (que, obviamente, han considerarse en el nivel de conocimiento léxico requerido), lo esencial es adquirir las herramientas constitutivas necesarias para descifrar y codificar unidades. Por ello, los ejercicios de orientación onomasiológica a partir de los valores sémicos primarios o secundarios de los constituyentes lexicogenésicos ${ }^{12}$ conllevan innegables ventajas en la fijación de los contenidos significativos ${ }^{13}$. En estos últimos casos se perciben en los constituyentes usos polivalentes bien diferenciados desde el punto de vista de la no discreción sinstrática-sinfásica, aunque escasamente visibles en los repertorios lexicográficos (García Platero, 2000). Piénsese en el formante -itis en ejemplos como amigdalitis, frente a titulitis, con el consiguiente valor disfemístico del segundo sentido del afijo, al igual que ocurre con -oide en romboide, frente a sentimentaolide. En el primer caso, del valor de 'inflamación' se pasa al de 'afición desmesurada o excesivo apego a algo o alguien', por lo que a la motivación morfológica hay que añadir en la noción peyorativa un empleo traslaticio. Por otra parte, este último afijo entra en clara competencia con el constituyente antepuesto (p)seudo- (seudointelectual), puesto que la acepción no especializada desarrolla un sentido de no veracidad, desde el momento en que la semejanza objetivable deviene en valor depreciativo, al no alcanzar el límite exigible de aceptación social. Se trata, como se verá, de un mecanismo similar al que se percibe en los sufijos diminutivos, en especial -illo, cuando se combinan con bases léxicas tanto de estimación inicial positiva como negativa, con una finalidad pragmática disfemística.

En algunos casos de aspectualidad sufijal polisémica al no estar presente la noción devaluativa, ya que se parte de un contenido a priori ortofemístico (al margen, obviamente de consideraciones discursivas pragmáticamente pertinentes), la relación entre sentidos resulta más opaca (como ocurre, por ejemplo, con -ero, dado que al valor de 'receptáculo de objetos' hay que añadir, entre otros, el agentivo). Esto no sucede, precisamente por el desarrollo peyorativo, con - $a d a^{14}$, en el que a partir de la idea de 'acción repentina', presente en voces como estocada, se percibe el carácter disfemístico de gamberrada o gansada (Lang, 1992: 175-178). Del mismo modo, no es extraño encontrarnos en los medios de comunicación, sobre todo en las columnas periodísticas, ejemplos como aznarada o zapaterada.

En la verbalización sabemos que, exceptuando los usos parasintéticos o las voces neonímicas, en las que efectivamente entra el sufijo - ar (al igual que ocurre con -ificar, pero sin tendencia a la parasíntesis), la mayor parte de las creaciones se obtienen con -izar y, sobre

12 En el sentido de desarrollos no etimológicos, esencialmente en los llamados elementos compositivos, que, en el fondo, dada su iteratividad y dispersión discursivas (pues traspasan lo estrictamente neonímico), adquieren suficiente vitalidad morfológica.

13 Por su productividad, también cabría destacar la importancia de la composición deverbal (Liceras, 2009).

14 Para un estudio exhaustivo del sufijo, cfr. Pujol (2009). 
todo, -ear, pues con -ecer únicamente nos encontramos con lexicalizaciones de sentido incoativo (como florecer). Pero lo que nos interesa, desde la perspectiva de este trabajo, es la tendencia a combinarse con nombres propios, puesto que uno de los valores de -ear es el iterativo, con una clara connotación disfemística ${ }^{15}$. En efecto, la creación léxica verbal a partir de nombres propios adquiere en español un contenido devaluativo, en la medida en que se resalta la habitualización de determinados actos generalmente vituperables de personajes públicos o privados, también visible en -izar (Martínez Linares, 2012). Es decir, el hablante subraya un rasgo negativo característico y descarta cualquier mención a otras cualidades. De ahí el valor peyorativo de creaciones, generalmente presentes en los medios de comunicación, independientemente de que sean o no esporádicas, como ocurre con $a z$ narear, pujolear, etc.

Subrayo estos casos porque los alumnos presentan problemas de identificación de los sentidos devaluativos de las unidades. Es preciso, por lo tanto, incidir en consideraciones de este tipo, válidas para reducir la opacidad léxica. Especialmente interesantes resultan, desde este enfoque, los vocablos formados por sufijación estrictamente no aspectual, aunque no hablemos con exactitud de discreciones, como hemos observado en los valores secundarios de los llamados elementos compositivos o en determinados empleos contextualmente disfemísticos de constituyentes no apreciativos. En efecto, el carácter potestativo de algunos formantes lexicogenésicos, dejando a un lado, lógicamente, las lexicalizaciones (por más que la perspectiva diacrónica arroje transparencia ${ }^{16}$ ), implica una inevitable carga de subjetividad en un continuo eufemístico-disfemístico ${ }^{17}$. En los constituyentes aumentativos y diminutivos comprobamos que se aminora la opacidad léxica al partirse de la idea de lo dimensional objetivo, únicamente por la coincidencia de múltiples subjetividades, a lo que se agregan sentidos meliorativos o peyorativos ${ }^{18}$. En general, lo dimensional, en su vertiente aumentativa o diminutiva, comporta connotaciones bien diferenciadas. Así, tradicionalmente se relaciona lo pequeño con lo positivo, al contrario que lo grande, lo que no impide que se intercambien las percepciones, en relación, generalmente, con las valoraciones de las bases léxicas con las que se combinan los formantes no aspectuales, como sucede con regalazo. La vitalidad de este último sufijo se percibe en la evolución del tradicional valor

15 Lang (1992: 215) cita ejemplos de empleos iterativos en voces verbalizadas como parpadear, relampaguear y chinchinear y esencialmente disfemísticos en discursear, fanfarronear y hombrear. Junto con la actualización del sema iterativo se ha hablado del carácter diminutivo (en el que puede entrar la dimensión subjetiva de valor disfemístico), como sucede con canturrear, pues la disminución léxica va más allá de lo nominal (Monterrubio Prieto, 1990).

16 En vocablos lexicalizados con sufijos no aspectuales, como molinillo, almohadón, telón o madrastra, se conservan rasgos dimensionales o estrictamente peyorativos que aminoran la opacidad, aunque se produzca la desparagramaticalización a la que se refería Lüdtke (1996: 83-84): "A funciones como predicado, sujeto o diminutividad, en la formación de palabras, las llamamos "paragramaticales" y a la formación de palabras "paragramática" o "gramática del léxico", porque el término de formación de palabras no permite ni siquiera la acuñación de un adjetivo de relación, menos aún la creación de términos para denominar procesos de cambios [...]. Se han desparagramaticalizado, por ejemplo, casi enteramente las funciones diminutiva y aumentativa en francés. Maisonnette no es sencillamente una maison diminutiva".

17 Si entendemos que el eufemismo y el disfemismo no son productos léxicos, sino procesos de actualización de recursos que pretenden minorar el referente interdicto o intensificarlo, según la realidad discursiva (Casas Gómez, 2009), se puede explicar que los problemas de descodificación o de adecuación contextual aparezcan al margen de catalogaciones apriorísticas.

18 Aunque algunos formantes se agrupen tradicionalmente dentro de los despectivos propiamente dichos, como ocurre con casucha. 
de 'golpe' (Monge, 1972), hasta llegar a creaciones disfemística, algunas más vinculadas que otras al contexto inmediato (decretazo, medicamentazo, tarjetazo, etc.), que ya vimos con la variante apreciativa del sufijo aspectual -ada. En el caso de -ón, por las mencionadas asociaciones dimensionales, los ejemplos de usos devaluativos no escasean, dando lugar a insultos que dejan, obviamente, de ser tales en la complicidad discursiva. Menos numerosas son las atenuaciones opacas, que se actualizan generalmente con la variante alomórfica del aumentativo (tontorrón).

En cuanto a los diminutivos, lo frecuente es el valor de atenuación (diablillo), más marcado en el caso de -ito, en el que la carga afectiva se intensifica (lo que encuentra parangón con la tendencia al empleo de abreviamientos en situaciones de informalidad, como cole, pelu, uni), con todos los matices pragmáticos de cortesía o modestia que podamos considerar (piénsese en el caso de regalito), por lo que en ciertas situaciones comunicativas lo minorativo puede interpretarse o no en su visión objetiva. Sin embargo, en más de una ocasión lo dimensional se concibe desde una óptica distinta, pues los referentes que se someten a juicio han de superar la aceptabilidad social, como se vio más arriba. De lo contrario, el vocablo pertinente que se adjunta con el afijo adquiere una dimensión disfemística. Así se percibe en politiquillo, curilla, jefecillo, mediquillo, etc. Esta posibilidad puede extenderse, incluso, a bases léxicas consideradas peyorativas, según la perspectiva cultural o ideológica de un número considerable de hablantes, por lo que cuando se añade el constituyente diminutivo se intensifica el valor apriorístico. La razón estriba en que, conviene reiterarlo, la dimensión minorativa juega en contra, en la medida en que, dentro del consenso devaluativo, no se alcanza, con matices, cierta respetabilidad. Esto sucede, desde las correspondientes ópticas ideológicas, con voces como como rojillo o fachilla (García Platero, 1997). En relación con lo señalado, podría entenderse que el continuo eufemístico-disfemístico, considerado como proceso de actualización de mecanismos, constituye un obstáculo insalvable en la búsqueda de la relativización de la arbitrariedad. Sin embargo, en lexicogénesis, incluso en las voces derivadas con constituyentes no aspectuales, donde el continuo dimensional implica rasgos no necesariamente objetivables, se evidencia la actualización de lo cuantitativo en función de determinadas realidades asumidas por la mayor parte de los hablantes. Es decir, en los vocablos en los que entran consideraciones de índole pragmática de cierta complejidad para la correcta descodificación resulta posible la minoración de la opacidad léxica atendiendo a una motivación que tenga en cuenta el conocimiento de las valoraciones socioculturales. El problema radica, en muchas ocasiones, en el tratamiento, en gran parte comprensible, tanto de los manuales como de los repertorios lexicográficos, al no poder abarcar la multiplicidad de sentidos de la apreciación y obviar las contextualizaciones pertinentes (Castillo Carballo y García Platero, 2006). Por ello, el docente debe recurrir a ejemplos más acordes con la perspectiva pragmática, a partir de corpus escritos y orales que muestren la no aspectualidad lexicogenésica en toda su amplitud ${ }^{19}$.

Por lo que respecta a la afijación antepuesta, la existencia de varios constituyentes que comparten identidad significativa implica, obviamente, una mayor dificultad, especialmente destacable con los formantes que denotan negación de la base léxica ${ }^{20}$ (no ocurre así en la polivalencia de extra-, al percibirse con facilidad el continuo entre el carácter locativo,

19 En relación con lo señalado, los enfoques por tareas, en sus diversas líneas de investigación (Ortega, 2004), poseen un interés indudable.

20 Para este tipo de prefijación debe verse Serrano-Dolader (2006). 
negativo e intensificador, por lo que el grado de relativa motivación es lógicamente mayor). Nos encontramos en esta, como en otras ocasiones, con una oposición entre la inteligibilidad estigmatizada, derivada de la aplicación analógica, entendida como el desarrollo de la capacidad generalizadora, sin tener en cuenta lo consuetudinario (a partir, por ejemplo, de la elección de un único formante para todo el paradigma ${ }^{21}$ ), y la no estigmatizada, que implica el conocimiento, sin demasiadas fisuras, de los empleos normativos. Hablamos de inteligibilidad, pues el destinatario del mensaje que domina la lengua meta no tiene problemas al descifrarlo, aunque la elección lexicogenésica no sea la convenida socialmente, al igual que ocurre con las irregularidades verbales, incluso entre nativos. Sin embargo, el conocimiento léxico del emisor queda en evidencia, frente a las situaciones que no conllevan una elección léxica arbitraria. De hecho, el propio hablante no foráneo se topa con motivaciones contextuales en el ámbito lexicogenésico, por diferentes razones ${ }^{22}$, por más que distinga la transgresión leve de las violentas, como ocurre, por ejemplo, con los adverbios en -mente (García Page, 1991). En todo caso, al margen de la anteposición o posposición del constituyente, como bien señala Serrano-Dolader (2005: 12), la sobregeneralización a la que tiende el aprendiz no es un problema esencial, pues el uso discursivo cotidiano subsana los posibles empleos no consensuados ${ }^{23}$, dado que "la enseñanza-aprendizaje de léxico no es en realidad un fin en sí mismo, ya que el léxico no es sino un medio para comunicarse y mejorar la competencia comunicativa".

En definitiva, en el ámbito de la formación de palabras cabe distinguir, desde la finalidad glosodidáctica, entre la no apreciación y apreciación lexicogenésica. Si en el primer caso, no nos encontramos con especiales problemas de opacidad, aunque sí con obstáculos normativos subsanables con el tiempo ${ }^{24}$, en el segundo las dificultades de descodificación y codificación se acentúan desde el momento en que son necesarios conocimientos de índole pragmática. Sin embargo la continuidad entre lo dimensional y determinadas connotaciones meliorativas o peyorativas, según los casos, pueden evidenciarse, por lo que la opacidad léxica se aminora. De ahí que se haya prestado especial atención a la no aspectualidad afijal.

21 Lo que demuestra que el discente ha interiorizado los mecanismos lexicogenésicos (Fernández López, 1992; Gómez Molina, 1997).

22 No hay que olvidar que el proceso de aprendizaje del léxico es gradual, por lo que determinados aspectos pueden no estar necesariamente cubiertos en un nivel determinado, tanto en los discentes foráneos como en los escolares nativos (Baralo, 2003), por lo que resultan lógicas las reanalizaciones de vocablos (Martín Vegas, 20032004; 2005). Los paralelismos entre el proceso de aprendizaje de la morfología compleja y la sintaxis son indudables, como señala (Varela 2003: 577-578): "Es plausible suponer que, en un sentido, la adquisición del léxico por parte del no-nativo se distancia del modo en que adquiere la sintaxis y que se asemeja mucho más al proceso que sigue el propio hablante nativo. En lo que se refiere al léxico derivado, el no-nativo desarrollaría presuntamente estrategias semejantes a las del nativo, basadas por lo pronto en su capacidad de segmentar o parcelar la palabra y de dotarla de significado a partir del de sus partes. De hecho, aún sin la base de investigaciones sólidas sobre el proceso de adquisición de la morfología léxica en L2, es práctica usual que las gramáticas pedagógicas planteen tareas de reconocimiento y producción del léxico complejo que en poco difieren de las que podemos encontrar en libros escolares destinados a que los hablantes nativos enriquezcan su vocabulario".

23 En muchas ocasiones, en las que no entran variaciones apreciativas, resulta ciertamente complejo encontrar una sistematización que implique transparencia entre los componentes del signo sin entrar en contradicción con los empleos consensuados. Así sucede con ciertos adjetivos denominales en -ble, como saludable (Gil Giménez, 1998).

24 Al margen de las contextualizaciones continuas, sin duda lo más rentable, algunas propuestas de ejercicios que inciden en la perspectiva onomasiológica pueden ser de ayuda (piénsese en las paráfrasis definitorias de profesiones que el aprendiz ha de adivinar utilizando el constituyente adecuado, como -ero o -ista). En cuanto a la anteposición lexicogenésica de valor negativo, son de utilidad los ejercicios referentes a la antonimia morfológica (posible, real, politico). 


\section{Las relaciones de semejanza y contigüidad}

La concepción tradicional de la metáfora (Ullmann, 1962) en la que se distinguían, entre otros, los empleos traslaticios antropomórficos (las manecillas del reloj), de los animalísticos (paso de cebra) y de los sinestésicos (voz cálida), ya poseía interés glosodidáctico, por la minoración de la opacidad léxica. Especial valor tienen los usos traslaticios cuando en el proceso de selección sémica metafórica se destaca una serie de comportamientos de animales para compararlos con los de las personas, no siempre visualizados en todas las culturas. Además, la recurrencia a la diminutividad en algunos casos (por ejemplo, hormiguita) ahonda en el continuo dimensional-afectivo ${ }^{25}$. En ese sentido, la reflexión metalingüística, cuando el nivel del discente lo permite, opera en beneficio del aprendizaje, rompe creencias etnocéntricas y consigue una empatía con la realidad léxica.

Por otra parte, es sabido que gracias a las aportaciones del cognitivismo la metáfora ha dejado de concebirse como una anomalía o desvío léxico, pues se enfatiza el conocimiento que el hablante posee de la realidad circundante ${ }^{26}$. De hecho, los procesos de pensamiento se consideran, en gran medida, metafóricos ${ }^{27}$. Es decir, se parte de la idea de que estamos ante una característica definidora de nuestro sistema mental, por más que se valga de la lengua y se refleje en ella ${ }^{28}$. De ahí la habitual diferenciación entre los esquemas abstractos que permiten la agrupación de expresiones traslaticias y sus correspondientes actualizaciones (Lakoff y Johson, 1980), de especial interés en el ámbito de la enseñanza de lenguas (Beréndi, Csábi y Kövecses, 2008). La perspectiva cognitivista toma en consideración experiencias humanas compartidas por culturas muy diversas ${ }^{29}$, por lo que se incrementa el nivel de transparencia. Los esquemas abstractos que se tienen en cuenta, por ejemplo la concepción cuantitativa en términos de verticalidad ("Ha subido la leche") o las ideas compartidas de que la vida es un viaje ("Juan nos ha dejado"), el amor es una guerra ("Lo conquisté con la mirada"), la mente es un recipiente ("No me cabe en la cabeza lo que vas a hacer"), las teorías son edificios ("Tiene argumentos poco sólidos") o las tareas son cargas ("Debes descargarte de trabajo"), dan lugar a que expresiones cotidianas sean fruto de la señalada reflexión. En cuanto al lenguaje político y al periodístico, nada desdeñables para nuestros fines (Romero Gualda, 2008: 235-237), con una clara

25 En relación con lo señalado, cabe resaltar la importancia de los culturemas (Luque Durán, 2007; Pamies Bertrán, 2009), entendidos como como símbolos culturales de especial importancia en el uso traslaticio del vocabulario, por lo que muestran hábitos y prejuicios reflejados en frases estereotipadas.

26 Cfr. el esclarecedor trabajo de Arribas Esteras (2009). Para una visión general de los usos metafóricos coloquiales, véase Fernández Colomer (2003).

27 Llamas Saíz (2005: 238) se refirió, con acierto, a la relativa motivación de las creaciones metafóricas, a partir de la visión cognitivista: "[...] el conocimiento del mundo que el hablante posee y sus ideas acerca de las cosas intervienen en la conformación del significado a partir de metáfora de un modo regular que puede sistematizarse mediante una serie de proyecciones que permiten hablar de una cierta coherencia metafórica. En este sentido, puede decirse que la ampliación del significado mediante metáfora está motivado, si bien no es posible saber el porqué de unas expresiones frente a otras".

28 Se ha dicho que esta perspectiva implica que nos encontremos ante una metalingüística que pretende explicar el lenguaje real (Martínez del Castillo, 2008: 188-195). Es decir, nos enfrentamos, una vez más, con expresiones acontextuales. En todo caso, conviene insistir en que la reflexión a la que aludimos, dejando a un lado estas observaciones, resulta de especial interés en el dominio del aprendizaje de lenguas.

29 Al margen del ámbito estrictamente traslaticio, pero en relación con las interrelaciones culturales, algunos estudios centrados en los aspectos contrastivos paremiológicos llegan a considerar, pese a las divergencias, importantes paralelismos interlingüísticos, como ocurre, por ejemplo, entre el español y el alemán (Zurdo, 1993). 
tendencia retroalimentativa, no son pocos los casos que pueden enumerarse a partir de los presupuestos cognitivistas. Resulta, de este modo, de interés la presencia de esquemas conceptuales y sus correspondientes expresiones traslaticias en el discurso parlamentario, analizadas con acierto por Sánchez García (2009): la política es una batalla ("Hay que luchar contra el paro"), la política es una mercancía ("Ya sabemos lo que vale su palabra"), el gobierno es un barco ("Es necesario enderezar el rumbo de la economía"), etc.

Incluso desde métodos de enseñanza y aprendizaje estrictamente inmersivos, son útiles los contrastes entre sistemas lingüísticos, el nativo y el correspondiente a la lengua meta, pues se aprovechan las ventajas de una concepción no anómala de los usos traslaticios y se aminoran, como se dijo más arriba, etnocentrismos, al evidenciarse identidades interculturales más intensas que las esperadas. Además, la consideración del no desvío del empleo metafórico consigue que el aprendiente entienda los procesos creativos de muchas unidades fraseológicas, caracterizadas precisamente por su idiomaticidad. Desde esta visión, conviene recordar que el ser humano parte del conocimiento de lo más inmediato, su propio cuerpo, sus necesidades primarias y los esfuerzos para alcanzarlas. Es un fenómeno de evolución semántica consabido que para nombrar lo nuevo se recurre intralingüísticamente a lo ya conocido. Del mismo modo, es connatural al hablante que acuda a lo tangible para designar conceptos y sentimientos. Casos como "Se cree el ombligo del mundo", "Es mi ojito derecho" o "Me saca las castañas del fuego" obedecen a esta necesidad de trasladar lo material cotidiano a sensaciones o comportamientos que, sin este proceder, eran inicialmente inefables. Si la adición significativa de los componentes de una unidad fraseológica no comporta su correcta descodificación, por su estructura metafórica unipolar, la minoración de la opacidad se consigue, precisamente, gracias al reconocimiento de experiencias con las que se visualizan nuestras raíces más profundas, al margen de las inevitables distancias culturales. Obviamente el grado de transparencia dependerá de los aspectos idiosincrásicos (Liceras y Carter, 2008: 388-390).

No cabe, por lo tanto, duda de que la conjunción entre la óptica cognitiva y la visión pragmática es esencial para un acercamiento al fenómeno glosodidáctico (Cepello Moreno y García Manga, 2012: 185):

En la actualidad se trata de explicar la naturaleza expresiva de la metáfora a partir de una aproximación conjunta desde la perspectiva pragmático-comunicativa y cognitiva. La pragmática inferencialista, en tanto que guía en el procesamiento lingüístico, encaja perfectamente en la perspectiva cognitiva del lenguaje, pues la pragmática ha de acudir a modelos cognitivos idealizados (aspectos del conocimiento del mundo sistematizados) para resolver los procesos de producción e interpretación de mensajes.

En la tarea de búsqueda de motivaciones relativas de las unidades léxicas en un sentido amplio, ocupan un lugar destacado los desplazamientos referenciales. De nuevo nos encontramos, a partir de los presupuestos señalados, con la adquisición de mecanismos que ayudan a la retención de determinados vocablos, tanto en el proceso codificador como descodificador. Así, la contigüidad presente en la designación del contenido con el significante del continente ("Se bebió la botella de vino"), en la de un producto con la expresión del lugar de procedencia ("Está muy bueno este jerez") o en la de un objeto con la mención al material con el que está hecho ("Compro oro"), junto con los habituales esquemas 
del todo por la parte ("Tiene muchas bocas que alimentar") o viceversa ("España ganó la Eurocopa"), debe tenerse muy en cuenta en el proceso de aprendizaje léxico. Incluso, en los niveles superiores, no son en absoluto desdeñables los fenómenos de antonomasias de cierta complejidad, en la medida en que dan lugar, incluso, a formas derivadas, lógicamente circunscritas a un determinado continuo sinstrático-sinfásico, como sucede con perogrullada, salomónico, platónico o rocambolesco. En estos ejemplos la motivación morfológica se une a la relación de contigüidad, lo que conlleva que el grado de opacidad quede aminorado, aunque se exijan los correspondientes datos históricos o culturales. De esta manera, especialmente productivas, en el nivel del conocimiento al que se hace referencia, son las tareas que animan al aprendiz a buscar las fuentes pertinentes y exponer en el aula el conocimiento enciclopédico adquirido, ya que, sin lugar a dudas, ayudan a la retención de este tipo de creaciones.

En trabajos clásicos como el de Le Guern (1973) se aludía a la experiencia extralingüística común entre los hablantes como resorte fundamental para entender estos desplazamientos. Es lógico suponer que la disminución motivadora es proporcional al estatuto lexicalizador de la unidad que ha experimentado el proceso de contigüidad, al igual que ocurre con los fenómenos metafóricos. Es decir, cuando se produce una verdadera alteración de la sustancia semántica (Sánchez Manzanares: 2007-2008). Por otra parte, es obvio que la descodificación metonímica dependerá de conocimientos referenciales, incluso para hablantes nativos. Sin embargo, la captación del proceso de contigüidad se evidencia en no pocos empleos (Sánchez Manzanares, 2009: 199):

Por otra parte, el desconocimiento de referentes de tipo cultural hace que no sean comprensibles metonimias como las de lugar por producto, o de autor por obra. Así, cuando se dice un Velázquez por un cuadro de Velázquez, la restitución de un cuadro no es clara para todo hablante de español, sino para un grupo social con un determinado nivel cultural, aunque se supone que la mayoría de los españoles ha accedido a un nivel educativo medio. Sin embargo, un hablante que desconozca que Velázquez es un pintor, no tiene por qué restituir un cuadro. Como nombre propio, puede identificar Velázquez con un antropónimo o un topónimo. Lo mismo sucede con la metonimia de lugar un Rioja, puesto que un hablante que ignore que la Rioja es una comarca en la que se elabora un vino con denominación de origen La Rioja no podrá identificarlo. No obstante, tanto en uno como en otro caso, los hablantes captan una relación de contigüidad que les lleva a interpretar la elipsis relacional, bien de lugar, bien de autor. Esto sucede porque el hablante es competente en la estructuración de los contenidos semánticos de su lengua -aunque ni siquiera para los especialistas sea posible describir la estructuración semántica del léxico-, y percibe una traslación referencial, un cambio denominativo. La determinación referencial por el artículo no llega a realizarse porque hay un desconocimiento del entorno semiótico de Velázquez o de Rioja, pero el hablante capta que hay una denotación oblicua porque hay una sustitución en el plano paradigmático que, en el caso de la metonimia, ocurre por una alteración en el nivel pre-sintagmático.

La captación de contigüidad, al margen del desconocimiento referencial, evidente en la lengua nativa, resulta lógicamente extensible, con las complejidades añadidas, a la lengua meta. Sin embargo hay que hacer hincapié cuando hablamos de aprendizaje léxico, por motivos lógicos, en la restitución de la unidad elidida. 


\section{Conclusiones}

Tanto la motivación relativa intralingüística como la que se basa en relaciones de semejanza o contigüidad con otras unidades tienen especial importancia en la glosodidáctica. Se ha subrayado que en el aprendizaje del vocabulario se observan no pocos desequilibrios, pues el discente presenta lagunas e inadecuaciones discursivas que persisten, pese a que se encuadre académicamente en un nivel global de conocimiento medio o alto. Las causas deficitarias se deben a que los métodos de enseñanza y aprendizaje no pueden, por las limitaciones de formato, abarcar la especificidad del léxico, por lo que no se plantean tareas adecuadas a la realidad inmediata. De ahí la necesidad de conjugar la adquisición incidental con la explícita para aumentar el lexicón del aprendiz. De esta manera, se huye de aproximaciones asistemáticas y se atiende a una adquisición gradual. En esta deseable complementariedad se ubican las reflexiones metalingüísticas, que entrañan el planteamiento de mecanismos minorativos de la opacidad léxica, especialmente útiles para quien pretende dominar una segunda lengua.

El aprendizaje de inmersión total no rivaliza con problemas de adecuación discursiva, ya que las unidades se manejan en su hábitat, con toda la plurivalidez comunicativa que esto implica. Sin embargo, cuando esto no es posible las carencias pueden paliarse con métodos que no necesariamente resultan pertinentes para hablantes nativos, pero sí para los que adquieren una lengua meta en circunstancias mucho menos propicias. En ese sentido, la recurrencia a textos mediáticos, caracterizados por la búsqueda de la expresividad léxica, es de especial interés, aunque hay de resaltar que lo básico no es el vocablo creado, no necesariamente perdurable, sino la aprehensión del mecanismo lexicogenésico y su valor pragmático.

En el acercamiento a la motivación intralingüística no hay que obviar los usos meliorativos y disfemísticos, de innegable relevancia pragmática, especialmente cuando nos situamos en la no aspectualidad afijal, dentro de un continuo dimensional-apreciativo. Y aunque se evidencie la idea, como se dijo más arriba, del eufemismo como proceso y no como producto, las catalogaciones léxicas tienden a marginar la incidencia pragmática al abordar los contenidos de los constituyentes, sobre todo los aumentativos y diminutivos. La mayor parte de los materiales didácticos olvidan la premisa de adecuación discursiva, tal vez por el escaso interés que el MCER ha mostrado ante el fenómeno, sobre todo cuando abordamos la no aspectualidad afijal. Es reseñable, en todo caso, que la sufijación ofrece más posibilidades de análisis que la prefijación, donde, por regla general, se atiende a la motivación morfológica que condiciona la adición de una base léxica a un constituyente antepuesto, aunque es frecuente que las restricciones normativas adquieran en la anteposición del formante lexicogenésico cierta relevancia.

Finalmente, conviene subrayar que los empleos traslaticios, junto con los antes aludidos ejemplos de contigüidad, son de especial interés, pues evidencian que no nos encontramos, sobre todo en el primer caso, únicamente con anomalías lingüísticas justificadas por los anhelos creativos del escritor, sino que son reflejo de esquemas derivados del conocimiento que los hablantes tienen de la realidad circundante, como bien se ha ocupado de defender la perspectiva cognitiva. Todo ello da lugar a la reflexión metalingüística, de indudable validez en el aprendizaje léxico, en el nivel de conocimiento pertinente, lo que contrasta con las necesidades, querencias y actos discursivos, tan rutinarios como libres, de quien maneja su lengua materna. 


\section{Referencias bibliográficas}

Alba Quiñones, V. de (2014): “Sobre diccionarios monolingües de aprendizaje de español y colocaciones léxicas. Estudio e implicaciones didácticas". En Garcés Gómez, M. ${ }^{\mathrm{a}}$ P. (ed.): Lexicografía teórica y aplicada. A Coruña, Universidade da Coruña, Anexos de Revista de Lexicografía, 26, págs. 119-133.

Alcón Soler, E. (2001): "Interacción y aprendizaje de segundas lenguas en el contexto institucional del aula". En Pastor Cesteros, S. y Ventura García Salazar (eds.): Tendencias y líneas de investigación en adquisición de segundas lenguas. Alicante, ELUA, Anexo 1, págs. 271-287.

Alvar Ezquerra, M. (2003): La enseñanza del léxico y el uso del diccionario. Madrid, Arco Libros.

Arribas Esteras, M. ${ }^{a}$ N. (2009): "Historias de las palabras: una propuesta antropológica y etnolingüística para el aprendizaje del léxico en ELE”. En Barrientos Clavero, A. (coord.): El profesor de español LE-L2. Actas del XIX Congreso Internacional de la Asociación para la Enseñanza del Español como Lengua Extranjera (ASELE). Cáceres, Universidad de Extremadura, págs. 185-202.

Baralo, M. (2003): "Lingüística aplicada: aprendizaje y enseñanza de español/LE", Interlingüística, 14, págs. 31-44.

Bartol Hernández, J. A. (2010): “Disponibilidad léxica y selección del vocabulario". En Castañer Martín, R. M. ${ }^{a}$ y V. Lagüéns Gracia (coords.): De moneda nunca usada. Estudios dedicados a José M. ${ }^{a}$ Enguita Utrilla. Zaragoza, Instituto Fernando El Católico, CSIC, págs. 85-107.

Benítez Pérez, Pedro (1994): "Léxico real/léxico irreal en los manuales de español para extranjeros". En Montesa Peydró, S. y A. M. Garrido Moraga (coords.): Actas del Segundo Congreso Nacional de ASELE. Madrid, ASELE, págs. 325-334.

Beréndi, M. , S. Csábi y Z. Kövecses (2008): “Using conceptual metaphors and metonymies in vocabulary teaching". En Boers, F. y S. Lindstromberg (eds.): Cognitive Linguistic Approaches to Teaching Vocabulary and Phraseology. Berlin, Mouton de Gruyter, págs. 65-100.

Calví, M. a V. y E. Martinell, (1998): "Los dobletes léxicos en la enseñanza del español a extranjeros". En Alonso, K; F. Moreno Fernández y M. ${ }^{a}$ Gil Bürmann (dirs.): El español como lengua extranjera: del pasado al futuro. Actas del VIII Congreso Internacional de ASELE. Madrid, Universidad de Alcalá de Henares, págs. 227-240.

Casas Gómez, M. (2009): "Hacia una nueva perspectiva de enfoque en la definición lingüística el eufemismo". En Fuentes Rodríguez, C. y E. R. Alcaide Lara (eds.): Manifestaciones textuales de la descortesía y agresividad verbal en diversos ámbitos comunicativos. Sevilla, Universidad Internacional de Andalucía, págs. 11-29.

Castillo Carballo, M. ${ }^{\text {a }}$ A. y J. M. García Platero (2006): "Valor pragmático de la apreciación en español". En Álvarez, A. et alii (eds.): La competencia pragmática y la enseñanza del español como lengua extranjera. Actas del XVI Congreso Internacional de ASELE. Oviedo, Universidad de Oviedo, págs. 208-212.

Castillo Carballo, M. A A. (2004): "La información colocacional en los diccionarios para L2". En Galloso Camacho, M. ${ }^{\mathrm{a}}$ V. y J. Prado Aragonés (eds.): Diccionario, léxico y cultura. Huelva, Universidad de Huelva, págs. 71-83. 
Cepedello Moreno, M. ${ }^{a}$ P. y M. C. García Manga (2012): “La motivación metafórica en el lenguaje: hacia una concepción cognitiva". En Calero Vaquera, M. ${ }^{a}$ L. y M. ${ }^{a}$ A. Hermosilla Álvarez (eds.): Lenguaje, Literatura y Cognición. Córdoba, Universidad de Córdoba, págs. 167-188.

Díaz Hormigo, M. ${ }^{a}$ T. (2009): "En torno a la teoría saussureana de la motivación lingüística”, ELUA, 23, págs. 73-98.

Escandell Vidal, M. ${ }^{\mathrm{a}}$ V. (2007): Apuntes de Semántica léxica. Madrid, UNED.

Fernández Colomer (2003): "La metáfora en español coloquial”, Interlingüística, 14, págs. 359-374.

Fernández López, S. (1992): "Formación de palabras y adquisición de la lengua". En Vázquez, C. y J. R. Losada (eds.): Actas del VIII Congreso Nacional de AESLA. Vigo, Universidad de Vigo, págs. 255-265.

García-Page, M. (1991): "El adverbio en -mente. Motivación contextual en formaciones léxicas “anómalas”, Anuario de estudios filológicos, 14, págs. 149-182.

García Platero, J. M. (1997): "Sufijación apreciativa y prefijación intensiva en español actual”, $L E A, 19,1$, págs. 51-62.

García Platero, J. M. (2000): "Presencia de las voces seudosufijadas en los diccionarios del español”. En Ruhstaller, S. y J. Prado Aragonés (eds.): Tendencias en la investigación lexicográfica del español. El diccionario como objeto de estudio lingüístico y didáctico. Huelva, Universidad de Huelva, págs. 425-432.

García Platero, J. M. (2002): “Aspectos semánticos de las colocaciones”, LEA, 24, 1, págs. 25-34.

García Platero, J. M. (2010): “La información semántica en los diccionarios de aprendizaje”. En Ruhstaller, S. y M. ${ }^{a}$ D. Gordón Peral (eds.): Diccionario y aprendizaje del español. Bern, Peter Lang, págs. 171-184.

Gil Jiménez, G. (1988): Aspectos gramaticales de la motivación lingüística. Málaga, Imprenta Montes.

Gómez Molina, J. R. (1997): “El léxico y su didáctica: una propuesta metodológica”, REA$L E$, 7, págs. 69-93.

Higueras García, M. (2006): Estudio de las colocaciones léxicas y su enseñanza en español como lengua extranjera. Málaga, ASELE.

Izquierdo Gil, M. ${ }^{a}$ del C. (2005): La selección del léxico en la enseñanza del español como lengua extranjera. Málaga, ASELE.

Jiménez Cuenca, M. A. (1999): “Consideraciones sobre creación y motivación en el léxico del español de Andalucía”. En Samper Padilla, J. A. y M. Troya Déniz (coords.): Actas del XI Congreso Internacional de la Asociación de Lingüística y Filología de la América Latina. Las Palmas de Gran Canaria, Universidad de Las Palmas de Gran Canaria, Librería Nogal, págs. 289-295.

Lakoff, G. y M. Johnson (1980): Metáforas de la vida cotidiana. Madrid, Cátedra.

Lang, Mervyn F. (1992): Formación de palabras en español. Morfología derivativa productiva en el léxico moderno. Madrid, Catedra.

Le Guern, M. (1973): Sémantique de la métaphore et de la métonymie. París, Larousse.

Liceras, J. M. y D. Carter (2008): "La adquisición del léxico". En De Miguel, E. (ed.): Panorama de la lexicología. Barcelona, Ariel, págs. 371-404.

Llamas Saíz, C. (2005): Metáfora y creación léxica. Navarra, Universidad de Navarra. 
López Morales, H. (1992): “En torno al aprendizaje del léxico. Bases psicolingüísticas de la planificación curricular”, RLA: Revista de lingüistica teórica y aplicada, 30, págs. 39-50.

Lüdtke, J. (1996): “La diacronía en la semántica de la formación de palabras”. En Henríquez Salido, M. ${ }^{\text {a }}$ do C. y A. Rifón (eds.): Estudios de morfología. A Coruña, Universidade de Vigo, págs. 77-90.

Luque Durán, J. D. (2007): “La codificación de la investigación lingüístico-cultural en los diccionarios interculturales". En Luque Durán, J. D. y A. Pamies (eds.): Interculturalidad y Lenguaje: El significado como corolario cultural. Granada, Método Ediciones, págs. 329-374.

Martín Camacho, J. C. (2007): “Observaciones sobre el papel de la analogía en los procesos morfológicos”, Revista de investigación Lingüística, 10, págs. 173-191.

Martín García, J. (1999): El diccionario en la enseñanza del español. Madrid, Arco Libros.

Martín Vegas, R. A. (2003-2004): "Evolución de la lingüística como ciencia cognitiva", Anuario de lingüística hispánica, 19-20, págs. 227-244.

Martín Vegas, R. A. (2005): “¿Segmentación morfemática o reanálisis? Formaciones con el sufijo -idad o *-abilidad, *-icidad, *-eidad”, Moenia, 11, págs. 269-281.

Martínez del Castillo, J. (2008): La lingüística cognitiva. Análisis y revisión. Madrid, Biblioteca Nueva.

Martínez Linares, M. ${ }^{\text {a }}$ A. (2012): “Aznarizar, zapaterizar... En torno a verbos forma sobre nombres propios con el sufijo -izar", LEA, XXXIV/2, págs. 247-275.

Méndez García de Paredes, E. (1993): "Valores asociados en la creación léxica". En Alcaide Lara, E. R.; M. ${ }^{a}$ del M. Ramos y F. J. Salguero (eds.): Estudios lingüísticos en torno a la palabra. Sevilla, Universidad de Sevilla, págs. 143-160.

Monge, F. (1972): "Sufijos españoles para la designación de golpe". En Homenaje a Francisco Ynduráin. Zaragoza, Facultad de Filosofía y Letras, págs. 229-247.

Monterrubio Prieto, J. M. (1990): “La disminución léxica, ¿un concepto exclusivamente nominal?", Verba, 17, págs. 77-92.

Morán Manso, M. (1999): "La enseñanza de E/LE con la metodología “Tandem”. En Losada Aldrey, M. ${ }^{\text {a }}$ C. y J. F. Márquez (coords.): Español como lengua extranjera, enfoque comunicativo y gramática: actas del IX congreso internacional de ASELE. Santiago de Compostela, Universidad de Santiago de Compostela, págs. 411-418.

Muñoz Liceras, J. (2009): "La morfología léxica del español y el llamado problema de la adquisición del lenguaje no nativo". En Serrano-Dolader, D.; M. 'A. Martín Zorraquino y J. F. Val Álvaro (eds.): Morfología y español como lengua extranjera. Zaragoza, Prensas Universitarias de Zaragoza, págs. 21-66.

Negro Alousque, I. (2010): "La traducción de las expresiones idiomáticas marcadas culturalmente”, Revista de lingüística y lenguas aplicadas, 5, págs. 133-140.

Ortega, L. (2004): “Aproximaciones cognitivo-interaccionistas al aprendizaje de segundas lenguas mediante tareas", Estudios de lingüística inglesa aplicada (ELIA), 5, págs. 15 40.

Pamies Bertrán, A. (2009): "Metáforas libres y metáforas lexicalizadas". En Luque Toro, L. (ed.): Léxico español actual II. Venezia, Università Ca’ Foscari Venezia, págs. 229-238.

Penadés Martínez, I. y M. ${ }^{a}$ T. Díaz Hormigo (2008): "Hacia la noción lingüística de motivación”. En Álvarez de la Granja, M. (ed.): Lenguaje figurado y motivación. Frankfurt am Main, Peter Lang, págs. 51-68. 
Pujol, I. (2009): “A propósito de los sustantivos en -ada: una reflexión metodológica del análisis de la formación de palabras en diacronía”, Cuadernos del Instituto Historia de la Lengua, 2, págs. 53-79.

Romero Gualda, M. ${ }^{a}$ V. (2008): Léxico del español como segunda lengua: aprendizaje y enseñanza. Madrid, Arco Libros.

Sánchez García, F. (2009): “Usos metafóricos del lenguaje político español. La metáfora estructural en los debates sobre el estado de la nación”. En Campos Gómez, P. y A. Sánchez Pérez (eds.): A Survey of Corpus-based Research. Panorama de investigaciones basadas en corpus. Murcia, AELINCO, págs. 1191-1207.

Sánchez Manzanares, M. C. (2007-2008): "Precisiones conceptuales en la definición de la sinécdoque como tropo metonímico", Pragmalingüística, 15-16, págs. 200-214.

Sánchez Manzanares, M. C. (2009): "Léxico y metonimia”. En Reyes, M. a J. (coord.): Léxicoy cultura.Badajoz,@becedario,págs.173-204.

Sánchez-Saus Laserna, M. (2010): “La variable 'nivel de español’ en el léxico disponible de los estudiantes de español como lengua extranjera", Pragmalingüística, 17, págs. 140-153.

Santamaría Pérez, M. ${ }^{a}$ I. (2006): La enseñanza del léxico en español como lengua extranjera. Alicante, Universidad de Alicante.

Serrano-Dolader, D. (2005): “La formación de palabras en español como lengua extranjera: reflexión y aplicación", Frecuencia L (Revista de Didáctica Español Lengua Extranjera), 28, págs. 11-15.

Serrando-Dolader, D. (2006): "La prefijación en la clase de ELE: los prefijos de valores negativos", Frecuencia L (Revista de Didáctica Español Lengua Extranjera), 32, págs. 11-15.

Soler Albiñana, M. ${ }^{a}$ (2008): “Aspectos relacionados con la enseñanza del léxico de E/ LE”. En Martí Contreras, J.; E. Peláez; A. Ortega y E. Lara (coords.): Teoría y práctica docente. Actas del II Congreso Internacional de Lengua, Literatura y Cultura de E/LE. University of Virginia, Món Editorial, Valencia, págs. 339-350.

Ullmann, S. (1962): Semántica. Introducción a la ciencia del lenguaje. Madrid, Taurus.

Varela Ortega, S. (2003): “Léxico, morfología y gramática en la enseñanza de español como lengua extranjera”, ELUA, 17, págs. 571-588.

Vidal, V. y M. ${ }^{\text {a }}$ T. Cabré (2005): "La combinatoria léxica en la enseñanza y aprendizaje de lenguas para propósitos específicos”. En Castillo Carballo, M. ${ }^{a}$ A.; O. Cruz Moya, J. M. García Platero y J. P. Mora Gutiérrez (coords.): Las gramáticas y los diccionarios en la enseñanza del español como segunda lengua: deseo y realidad. Sevilla, ASELE, Universidad de Sevilla, Universidad Pablo de Olavide, págs. 896-902.

Zurdo, M. ${ }^{a}$ T. (1993): "Motivación situacional del léxico de los Refranes/Sprichwörter. Contribución a un análisis intercultural”, Revista de Filología Alemana, 1, págs. 197-215. 